\title{
Üç Kamu Üniversite Hastanesinde Gerçekleștirilen Kardiyoloji ve Kalp Damar Cerrahisi Ișlemlerinde Paket Fiyat Uygulamalarının Değerlendirilmesi
}

\author{
Assessment of Package Price Applications in Cardiology and Cardiovascular Surgery Operations in Three Public \\ University Hospitals
}

Tuğba Denge ${ }^{1}$, Atilla Aral2, İsmail Ağırbaș 3

Ankara Üniversitesi Tıp Fakültesi, Faturalama Birimi, Ankara, Türkiye Ankara Üniversitesi Tip Fakültesi Kalp Damar Cerrahisi Anabilim Dalı Faturalama Birimi, Ankara, Türkiye

Ankara Üniversitesi Sağlık Bilimleri Fakültesi, Sağık Kurumları Yönetimi Bölümü, Ankara, Türkiye

Amaç: Ankara ilindeki üç kamu üniversite hastanesinde 2012 yılı içinde Kardiyoloji ve Kardiyovasküler Cerrahi (KVC) kliniklerinde yapılan paket ișlemlerin değerlendirilmesi amaçlanmıștır.

Gereç ve Yöntem: Hastanelerin Kardiyoloji ve KVC Kliniklerinde 2012 yılı içinde yapılan 12998 adet paket ișlemin kayıtları retrospektif olarak incelendi. İnceleme sonrası araștırmaya A hastanesi KVC için 705 , Kardiyoloji için 2719, B hastanesi KVC için 335, Kardiyoloji için 1005 ve C hastanesi KVC için 321, Kardiyoloji için 2556 adet ișlem dahil edilmiștir.

Bulgular: A hastanesi Kardiyoloji ișlemlerinin \%65,3'ünde paket așımı olduğu ve ortalama zararın -353,9 TL olduğu, KVC ișlemlerinin \%61,5'inde paket așımı olduğu ve ortalama zararın -651,7 TL olduğu, B hastanesi Kardiyoloji ișlemlerinin \%25,4'ünde paket așımı olduğu ve ortalama kârın 34,1 TL olduğu, KVC ișlemlerinin \%31,3'ünde paket așımı olduğu ve ortalama kârın 434,0 TL olduğu, C hastanesi Kardiyoloji ișlemlerinin $\% 43,2$ 'sinnde paket așımı olduğu ve ortalama zararın $-119,9$ TL olduğu, KVC ișlemlerinin $\% 41,7$ 'sinde paket așımı olduğu ve ortalama kârın 764,6 TL olduğu görülmüștür.

Sonuç: Üç kamu üniversite hastanesinde gerçekleștirilen kırk üç farklı Kardiyoloji ve KVC ișleminin on dördünde tahakkuk zararı oluștuğu ve bu sebeple bu ișlemler için paket fiyatlarının yeterli olmadığı ifade edilebilir. Öte yandan KVC ișlemlerinde tahakkuk kârı olușturan sekiz ișlem için paket fiyatlarının yeterli olduğu anlașıldı. Sonuç olarak, Sağlık Uygulama Tebliği'nin iki listesi ( hizmet bașına ödeme listesi ve tanıya dayalı ișlem listesi) arasında fiyat bakımından korelasyon olmadığı öngörülebilir.

Anahtar Sözcükler: Hastane, Paket Fiyat, Sağlık Uygulama Tebliği, Kardiyoloji, Kardiyovasküler Cerrahi

Objective: The assessment of package operations held in 2012, in Cardiology and Cardiovascular Surgery (CVS) clinics of three public university hospitals in Ankara was aimed.

Material and Method: The data of 12988 package operations held in 2012, in Cardiology and Cardiovascular Surgery (CVS) clinics of the hospitals were investigated retrospevtively. After investigation, 705 CVS and 2719 Cardiology package operations of A Hospital, 335 CVS and 1005 Cardiology package operations of B Hospital and 321 CVS and 2556 Cardiology package operations of C Hospital were included in this research.

Results: It was observed that $65,3 \%$ of Cardiology operations of A hospital was out of package and average loss was $-353,9 \mathrm{TL}, 61,5 \%$ of CVS operations of A Hospital was out of package and average loss was $-651,7 \mathrm{TL}$, $25,4 \%$ of Cardiology operations of B Hospital was out of package and average profit was $34,1 \mathrm{TL}, 31,3 \%$ of CVS operations of B Hospital was out of package and average profit was $434,0 \mathrm{TL}, 43,2 \%$ of Cardiology operations of C Hospital was out of package and average loss was $-119,9$ TL, $41,7 \%$ of CVS operations of C Hospital was out of package and average profit was $764,6 \mathrm{TL}$.

Conclusion: It can be stated that there were accural losses in fourteen of fortythree different Cardiology and CVS operations held in three public hospitals and the package prices therefore weren't sufficient for those fourtythree operations. On the other hand, it was observed that the package prices were sufficient for eight CVS operations in which accrud profit ensured. As a consequence; it can be forseen that there is no correlation between the two lists of Health Application Services, Payment List Per Service and Operations List Based on Diagnosis, in terms of prices.

Key words: Hospital, Package Price, Health Application Service, Cardiology, Cardiovasculer Surgery

Gelişen teknoloji ile birlikte sağlık harcamalarının giderek artması gelişmiş ve gelişmekte olan ülkeler için sorun teşkil etmektedir.(1) Ulusal sağlık sistemlerinin karșı karșıya kaldığı ortak sorun tıbbi bakım maliyetlerinin ulusal gelirden artan miktar ve oranda pay almasıdır.(2) Sağlık harcamalarının sürekli artışı nedeniyle maliyetlerin kontrolü için politika belirleyiciler farklı yöntemler kullanma yoluna gitmektedir. Bu yöntemler ile sağlık hizmeti için yapılan harcamalar kontrol altında tutulurken, insanların ihti- 
yaçları olan sağlık hizmetlerini almalar1 amaçlanmaktadır.(3) Ödeme yöntemlerinde tek bir yöntemi uygulamak yerine değişik yöntemleri içeren karma ödeme modelleri kullanılmaktadir.(4) Kurumsal sağlik hizmet sunucularına ödemeler; sosyal sigorta kurumlar1, sağlik sigorta şirketleri veya diğer hükümet kurumları ile özel ve tüzel kişilikler tarafindan kurumsal sağlık hizmet sunucularına yapılan ödemeler veya kaynak aktarımı olarak tanımlanmaktadır.(5) Ödeme yöntemleri sabit ve değişken sistemler ve geriye ve ileriye dönük sistemler olarak iki şekilde sınıflanabilir.(4) Sabit ve değişken geri ödeme sistemleri arasindaki fark, sunulan hizmet hacmi ve yapılan ödemeler arasındaki ilişkiye dayanmaktadır.(6) Geriye ve ileriye dönük ödemeler arasında dikkat çeken unsur ise geriye dönük ödemelerde sunulan her hizmet için oluşan maliyetin karşılanabiliyor olmasıyken, ileriye dönük ödemelerde sunulan her hizmetin maliyetinin karșılanmasında kurum açısından finansal risk bulunmaktadir.(6)

Sağlık kurumlarına yapılan geri ödeme yöntemleri; bütçe ödemesi, hizmet başına ödeme, günlük ödemeler, kişi başına ödeme, vaka başına ödeme ve düz oranda ödemedir.(7) Sağl1k sistemlerinde kullanılan ödeme yöntemlerinin hepsinin avantaj1 ve dezavantaj1 bulunmaktadır. Her ülke, geri ödeme yöntemini kendine has özelliklerini değerlendirerek belirlemelidir.(8) Türkiye'de kamu sağlık kurumlarının tamamı, özel sağlık kurumlarının da büyük çoğunluğu geri ödeme kurumu olan Sosyal Güvenlik Kurumu (SGK) ile sözleşme yapmaktadır. SGK geri ödemeleri Sağlık Uygulama Tebliğinde (SUT) belirtilen hükümlere göre yapmaktadır. Sağlık Uygulama Tebliği 5502 sayılı Sosyal Güvenlik Kurumu Kanunu, 5510 sayılı Kanun ve Genel Sağlık Sigortası İşlemleri Yönetmeliği çerçevesinde düzenlenmiş bir geri ödeme yönergesidir. Sağlık Uygulama Tebliği; Sosyal Güvenlik Kurumu'nca finansmanı sağlanan sağlık hizmetlerinin neler olduğu, sağlık hizmetlerinin bedelleri, bu hizmetlerden nasil yararlanılacağı̆, başvuru yöntemleri, başvuruda gerekli olan belgeler, sağlık hiz- meti sunucularının basamaklandırılması, ilave ücretin ne olduğu, üst sını$\mathrm{r1}$, ilave ücret alınmayacak kişiler ve haller, katılım payı miktarı, katılım pay1 alınmayacak kişiler ve haller, tahsil yerleri ve yöntemleri, yol ve gündelikler ile bunlara ilişkin bașvuru yöntemleri, kapsamdaki kișiler gibi hem genel sağlık sigortalısını ve bakmakla yükümlü olduğu kişileri hem de sağlık hizmeti sunucusunu ilgilendiren ve uyulması gerekli kurallar ve bilgileri içeren Resmi Gazete'de yayımlanan tebliğdir.(9) Devlet, sağlik hizmetlerinin hakkaniyet içinde verilebilmesi ve her yerde eşit sağl1k hizmeti verilmesini sağlamak amaciyla bu sektöre müdahale etmektedir.(10) Devlet sahip olduğu imkânlarla kişilere daha kaliteli sağlık hizmeti sunabilmek için yeni uygulamalara başvurabilmektedir.(11) Paket işlem fiyat uygulaması da bunlardan birisi olmaktadır. Sağlık işletmelerinin maliyetlerin doğru olarak belirlenmesi, hem sağlık işletmesindeki girdilerin planlanması ve kontrolü, hem de sunulan sağlık hizmetlerinin fiyatlandırılması bakımından oldukça önemlidir.(12) "Tanıya dayalı (paket) fiyat; dâhili ve cerrahi branşlarda sık karşılaşılan hastalıkların tanı ve tedavisi sırasında hizmet içeriği bakımından hasta bazında çok fazla değişiklik göstermeyen ve bu nedenle yaklaşık maliyeti önceden tahmin edilebilen tüm işlemlerin tek bir fiyat olarak belirlenmesidir". Burada tanımlanan paket, tüm masrafların dâhil olduğu, tek fiyatın geçerli olduğu bir kavramdır. Hastanın, hastaneye yatışından taburcu oluncaya kadar yapilan tüm masraflar için tek bir fiyat geçerlidir. Bu fiyatın içerisine, hastanın taburcu olduktan sonraki döneminde (paket süresine on gün eklenir) yapilan kontrollerin maliyetleri de dâhil edilmiştir.(13) Bu çalışmada Kardiyoloji ve Kardiyovasküler Cerrahi (KVC) paket işlemlerinin değerlendirilmesi, paket aşımlarının belirlenmesi ve SUT fiyatlarıyla karşılaştırılması hedeflenmiştir.

\section{Gereç ve Yöntem}

Araştırma, Ankara ilindeki üç kamu üniversite hastanesinde 2012 yilı içinde Kardiyoloji ve KVC kliniklerinde yapılan pa- ket işlemlerin değerlendirilmesi amacı ile yapilmiştır.

\subsection{Araștırmanın Evreni ve Ör- neklemi}

Ankara ilindeki üç kamu üniversite hastanesinde 2012 y1l içinde Kardiyoloji ve Kalp Damar Cerrahisi kliniklerinde yapılan paket işlemler evren olarak belirlenmiştir. Örneklem çekilmemiş olup, evrenin tamamı araştırma kapsamına alınmıştır. Bu işlemlerden A üniversitesi hastanesi KVC kliniğine ait 1818, Kardiyoloji kliniğine ait 4267 adet paket ișlem, B üniversitesi hastanesi KVC kliniğine ait 1118, Kardiyoloji kliniğine ait 2007 adet paket işlem ve $C$ üniversitesi hastanesi KVC kliniğine ait 506, Kardiyoloji kliniğine ait 3282 adet paket işlemin kayitlar1 retrospektif olarak incelenmiştir. İnceleme sonrası sehven tahakkuk edildiği anlaşılan tutarsız paket işlemler, Radyoloji Ana Bilim Dalı ile ortak yapılan işlemler, yoğun bakım paketleri, aynı seansta birden fazla operasyonun yapıldığ1 paketler ve branş dişı işlemler çalışma dişında b1rakılmışlardır. Araştırmaya A üniversitesi hastanesi KVC kliniği için 705, Kardiyoloji kliniği için 2719, B üniversitesi hastanesi KVC kliniği için 335, Kardiyoloji kliniği için 1005 ve C üniversitesi hastanesi KVC kliniği için 321, Kardiyoloji kliniği için 2556 adet işlem dahil edilmiştir.

\subsection{Verilerin Toplanması ve De- ğerlendirilmesi}

Veriler, Ankara ilindeki üç kamu üniversite hastanesinin yönetim birimlerinden yazılı izinler alındıktan sonra hastanelerin tıbbi, idari ve teknik kayıtlarından yararlanılarak toplanmıştır. Üç üniversite hastanesinin KVC ve Kardiyoloji kliniklerinde yapılan işlemlerde paket aşımı olup olmadı̆̆1, varsa ne düzeyde olduğu değerlendirilmiştir. Bu değerlendirme, Sosyal Güvenlik Kurumu 2012 SUT fiyatları dikkate alınarak yapılmıştır. Tespit edilen paket aşımları hastanelerin teknik kayıtlarında her işlem için tanımlanmış olan paket kimlik numaraları (ID) kullanılarak paket detayları elektronik veriler üzerinden incelenmiș ve ta- 
hakkuk zararına neden olan harcama kalemleri ortaya konmuştur. Hastaneler tek tek, kendi aralarında ve toplu olarak karşılaştırılmıştır.

\subsection{Araștırma Yöntemi}

Bütün veriler elektronik ortamda tutulan kayıtlardan elde edilmiş, bilgisayar desteği ile Microsoft Office 2013 Excel programı aracilığ1 ile analiz edilmiştir.

\section{Bulgular}

Çalışma kapsamında bulunan üç kamu üniversite hastanesinin Kardiyoloji ve KVC kliniklerinde 2012 yllında yap1lan paket işlemler incelendiğinde, A hastanesi Kardiyoloji işlemlerinin \%65,3'ünde paket aşımı olduğu ve ortalama zararın -353,9 TL olduğu, KVC işlemlerinin \%61,5'inde paket aşımı olduğu ve ortalama zararın 651,7 TL olduğu, B hastanesi Kardiyoloji işlemlerinin \%25,4'ünde paket aşımı olduğu ve ortalama kârın 34,1 TL olduğu, KVC işlemlerinin \%31,3'ünde paket aşımı olduğu ve ortalama kârın 434,0 TL olduğu, C hastanesi Kardiyoloji işlemlerinin \%43,2'sinde paket aşımı olduğu ve ortalama zararın -119,9 TL olduğu, KVC işlemlerinin \%41,7'sinde paket aşımı olduğu ve ortalama kârın 764,6 TL olduğu görüldü (Tablo 1).

$A$ ve $B$ hastaneleri Kardiyoloji ortak işlemleri karşılaştırmalı olarak incelendiğinde, 24 işlemin her iki hastanede de yapıldığ́ görüldü. Bu 24 işlem kapsaminda A hastanesinde 2543, B hastanesinde 1004 adet işlem yapıldı̆̆1 ve A hastanesi Kardiyoloji işlemlerinin \%65,8'inde paket aşımı olduğu, \%34,1'inde olmadığ1 ve ortalama zararın -328,2 TL olduğu, B hastanesi Kardiyoloji işlemlerinin $\% 25,5$ 'inde paket aşımı olduğu, $\% 74,5$ 'inde olmadiğ1 ve ortalama kârın 33,7 TL olduğu görüldü.

A ve B hastaneleri KVC ortak işlemleri karşılaştırmalı olarak incelendiğinde, 43 işlemin her iki hastanede de yapıldığ görüldü. Bu 43 işlem kapsaminda A hastanesinde 600, B hastanesinde 279 adet işlem yapıldı̆̆ı ve A hastanesi
KVC işlemlerinin \%61,6'sında paket aşımı olduğu, \%38,3’ünde olmadığı ve ortalama zararın -600,5 TL olduğu, B hastanesi KVC işlemlerinin \%31,5'inde paket aşımı olduğu, \%68,4'ünde olmadığ1 ve ortalama kârın 399,6 TL olduğu görüldü (Tablo 2).

A ve C hastaneleri Kardiyoloji ortak işlemleri karşılaştırmalı olarak incelendiğinde, 28 işlemin her iki hastanede de yapıldığ1 görüldü. $\mathrm{Bu} 28$ işlem kapsaminda A hastanesinde 2630, B hastanesinde 2409 adet işlem yapıldığ́1 ve A hastanesi Kardiyoloji işlemlerinin \%65,4'ünde paket aşımı olduğu, \%34,6'sında olmadiğ1 ve ortalama zararın $-327,8$ TL olduğu, C hastanesi, Kardiyoloji işlemlerinin $\% 41,5$ 'inde paket aşımı olduğu, \%58,4'ünde olmadığ1 ve ortalama zararın -88,6 TL olduğu görüldü.

A ve $C$ hastaneleri KVC ortak işlemleri karşılaştırmalı olarak incelendiğinde, 33 işlemin her iki hastanede de yapıldığ1 görüldü. Bu 33 işlem kapsamında A hastanesinde 373, C hastanesinde 194 adet işlem yapıldığı ve A hastanesi KVC işlemlerinin \%46,9'unda pa- ket aşımı olduğu, \%53,0'1nda olmad1ğ1 ve ortalama kârın 736,4 TL olduğu, C hastanesi KVC işlemlerinin \%34,5'inde paket aşımı olduğu, \%65,4'ünde olmadiğı ve ortalama kârın 983,8 TL olduğu görüldü (Tablo 3$)$.

$B$ ve C hastaneleri Kardiyoloji ortak işlemleri karşılaştırmalı olarak incelendiğinde, 21 işlemin her iki hastanede de yapıldığ görüldü. Bu 21 işlem kapsaminda B hastanesinde 996, C hastanesinde 2295 adet işlem yapıldığ1 ve B hastanesi Kardiyoloji işlemlerinin \%25,6'sında paket aşımı olduğu, \%74,4'ünde olmadığı ve ortalama kârın 29,2 TL olduğu, C hastanesi Kardiyoloji işlemlerinin \%39,7'sinde paket aşımı olduğu, \%60,2'sinde olmadığı ve ortalama zararın -75,5 TL olduğu görüldü.

$B$ ve C hastaneleri KVC ortak işlemleri karşılaştırmalı olarak incelendiğinde, 34 işlemin her iki hastanede de yapıldığ1 görüldü. Bu 34 işlem kapsamında B hastanesinde 196, C hastanesinde 196 adet işlem yapıldığı ve B hastanesi, KVC ișlemlerinin \%34,6'sında paket

Tablo 1: Hastanelerin Değerlendirmesi

\begin{tabular}{lcccc} 
Hastane & İșlem Sayısı & Paket Așımı Olan \% & Paket Așımı Olmayan \% & Ortalama Gelir TL \\
\hline A Kardiyoloji & 2719 & 65,3 & 34,6 & $-353,9$ \\
B Kardiyoloji & 1005 & 25,4 & 74,5 & 34,1 \\
C Kardiyoloji & 2556 & 43,2 & 56,7 & $-119,9$ \\
A KVC & 705 & 61,5 & 38,4 & $-651,7$ \\
B KVC & 335 & 31,3 & 68,6 & 434,0 \\
C KVC & 321 & 41,7 & 58,2 & 764,6
\end{tabular}

Tablo 2: A Hastanesi ile B Hastanesinin Karşılaştırılması

\begin{tabular}{lllll} 
Hastane & İșlem Sayısı & Paket Așımı Olan \% & Paket Așımı Olmayan \% & Ortalama Gelir TL \\
\hline A Kardiyoloji & 2543 & 65,8 & 34,1 & $-328,2$ \\
B Kardiyoloji & 1004 & 25,5 & 74,5 & 33,7 \\
A KVC & 600 & 61,6 & 38,3 & $-600,5$ \\
B KVC & 279 & 31,5 & 68,4 & 399,6
\end{tabular}

Tablo 3: A Hastanesi ile C Hastanesinin Karşılaştırılması

\begin{tabular}{lllll} 
Hastane & İșlem Sayısı & Paket Așımı Olan \% & Paket Așımı Olmayan \% & Ortalama Gelir TL \\
\hline A Kardiyoloji & 2630 & 65,4 & 34,6 & $-327,8$ \\
C Kardiyoloji & 2409 & 41,5 & 58,4 & $-88,6$ \\
A KVC & 373 & 46,9 & 53,0 & 736,4 \\
C KVC & 194 & 35,5 & 65,4 & 983,8
\end{tabular}


aşımı olduğu, \%65,3’ünde olmadığ1 ve ortalama kârın 572,3 TL olduğu, C hastanesi KVC işlemlerinin \%30,1' inde paket aşımı olduğu, \%69,9'unda olmadığ1 ve ortalama kârın 643,4 TL olduğu görüldü (Tablo 4).

A, B ve C hastaneleri Kardiyoloji ortak işlemleri karşılaştırmalı olarak incelendiğinde, 21 işlemin her üç hastanede de yapıldığ1 görüldü. $\mathrm{Bu} 21$ işlem kapsaminda A hastanesinde 2532, B hastanesinde 996, C hastanesinde 2295 adet işlem yapıldığı ve A hastanesi Kardiyoloji işlemlerinin \%65,9'unda paket aşımı olduğu, $\% 34,0$ '1nda olmadığı ve ortalama zararın -327,3 TL olduğu, B hastanesi Kardiyoloji isslemlerinin \%25,6'sinda paket aşımı olduğu, \%74,4'ünde olmadığ1 ve ortalama kârın 29,2 TL olduğu, C hastanesi, Kardiyoloji işlemlerinin $\% 39,7$ 'sinde paket aşımı olduğu, \%60,2'sinde olmadı̆g1 ve ortalama zararın -75,5 TL olduğu görüldü.

A, B ve C hastaneleri KVC ortak işlemleri karşılaştırmalı olarak incelendiğinde, 22 işlemin her üç hastanede de yapıldığı görüldü. Bu 22 ișlem kapsamında A hastanesinde 331, B hastanesinde 188, C hastanesinde 163 adet işlem yapıldığı ve A hastanesi KVC işlemlerinin \% 45,0 'ında paket aşımı olduğu, $\% 54,9$ 'unda olmadığ1 ve ortalama kârın 678,8 TL olduğu, B hastanesi KVC işlemlerinin \%35,5'inde paket aşımı olduğu, \%66,4'ünde olmadığ1 ve ortalama kârın 489,7 TL olduğu, C hastanesi KVC işlemlerinin \%33,1' inde paket aşımı olduğu, \%66,8'inde olmadığ1 ve ortalama kârın 411,9 TL olduğu görüldü (Tablo 5).

\section{Tartıșma ve Sonuç}

Bir ülkenin en önemli kaynağı insandır. Birey ve toplum hayatında önemli bir yeri olan sağlık ve sağlık hizmetleri için yapılan harcamalar giderek artmaktadır.(3) Tüm ülkelerde, devletin sağlık harcamalarına ayırdığı kaynak ve bu kaynağın kullanım şekli çeşitli platformlarda sı tartışılmakta ve eleştirilmektedir.(14) Kamu ve özel sektör tarafindan yürütülen politikalar sağlık hizmetlerini doğrudan etkilemektedir. Bu nedenle, sağllk hizmet-

Tablo 4: B Hastanesi ile C Hastanesinin Karşılaştırılması

\begin{tabular}{lcccc} 
Hastane & İșlem Sayısı & Paket Așımı Olan \% & Paket Așımı Olmayan \% & Ortalama Gelir TL \\
\hline B Kardiyoloji & 996 & 25,6 & 74,4 & 29,3 \\
C Kardiyoloji & 2295 & 39,7 & 60,2 & $-75,5$ \\
B KVC & 196 & 34,6 & 65,3 & 572,3 \\
C KVC & 196 & 30,1 & 69,9 & 643,3
\end{tabular}

Tablo 5: A Hastanesi, B Hastanesi ve C Hastanesinin Karşılaştırılması

Hastane Ișlem Sayısı Paket Așımı Olan \% Paket Așımı Olmayan \% Ortalama Gelir TL

\begin{tabular}{lcccc}
\hline A Kardiyoloji & 2532 & 65,9 & 34,0 & $-327,3$ \\
B Kardiyoloji & 996 & 25,6 & 74,4 & 29,3 \\
C Kardiyoloji & 2295 & 39,7 & 60,2 & $-75,5$ \\
A KVC & 331 & 45,0 & 54,9 & 678,8 \\
B KVC & 188 & 35,5 & 66,4 & 489,7 \\
C KVC & 163 & 33,1 & 66,8 & 411,9
\end{tabular}

leriyle ilgili kararların bilimsel kanıtlara dayanması gerekmektedir.(3) Türkiye' de paket fiyat uygulamaları sadece belli hastalık gruplarında uygulanmaktadır. Uygulanmakta olan paket fiyatlardaki ücretlerin gerçek maliyetleri yansıtmadığı konusunda hizmet sunucularından özellikle de üniversite hastanelerinden eleştiriler gelmektedir. Üniversite hastaneleri, özellikle tedavi maliyeti yüksek hastalıkların tedavisiyle ilgilendiğinden paket fiyatlarda tespit edilen ücretlerin kendi standartlarındaki tedavi maliyetlerini karşılamaktan uzak olduğunu ifade etmektedirler.(1)

Yilmaz ve ark.(15) klinik uygulamada, standart bir koroner anjiyografi işlemi ile gider artırıcı risk faktörlerine sahip bir hastaya uygulanan anjiyografi işleminin eşit kabul edilemeyeceği, bu durum gözetilerek, böbrek yetersizliği riski altındaki bir hastada olduğu gibi ek gider getiren özel durumlardaki hastalarda bu gideri karşılayacak mekanizmaların bulunması gerektiği, koroner anjiyografi sonrasinda diyabetik ve kronik böbrek yetersizliği olan hastaların \%48'inde kreatinin değerlerinin yükseldiği göz önüne alınırsa oluşabilecek akut böbrek yetersizliği ya da hastanede yatış sürecindeki uzamaya neden olan diğer durumların giderleri ne ölçüde etkileyeceğinin anlaşılacağını ortaya koymuştur.(15)
Çalışmada analizi yapılan hastalar için SGK' na fatura edilen paket fiyat tutarları ile aynı işlem için hastanenin tahakkuk ettiği hizmetlerin toplam rakamları karşılaştırılarak paket aşımı olan ve olmayan işlemler incelendiğinde KVC için üç hastanede ortak yap1lan işlemlerin karşılaştırmalı analizinde tahakkuk zararı oluşan işlemlerin;

- By-pass greft, ven dişındakilerle, femoral-femoral (P607300)

- Embolektomi/trombektomi, femoropopliteal,aortoiliak arter,bacak insizyonu (P606030)

Koroner arter by-pass, otojen greft (Safen/IMA vb.), tek koroner grefti, kardiyopulmoner bypass ile (P605000) olduğu tahakkuk kârı olan işlemlerin ise;

Asendan aorta grefti, kardiopulmoner by-pass ile, koroner implant var (P605680)

- Koroner arter by-pass, otojen greft (safen/IMA vb.), tek koroner grefti (P604940)

- Koroner arter by-pass, otojen greft (safen/IMA vb.), beş koroner grefti, kardiyopulmoner bypass ile (P604960)

Koroner arter by-pass, otojen greft (safen/IMA vb.), dört koroner grefti, kardiyopulmoner bypass ile (P604980) 
- Koroner arter by-pass, otojen greft (safen/IMA vb.), iki koroner grefti, kardiyopulmoner bypass ile (P604930)

- Koroner arter by-pass, otojen greft (safen/IMA vb.), üç koroner grefti, kardiyopulmoner bypass ile (P604950)

- Replasman, aort kapağ1 (P604610)

- Replasman, mitral kapak (MVR) (P604710) olduğu görülmüştür.

Çalışma kapsamında üç hastanede de yapılan ortak işlemlerin karşılaştırmalı analizinde Kardiyoloji için tahakkuk zararı oluşan işlemlerin;

- Basınç veya Doppler teli ile intrakoroner hemodinamik çalışma (P700811)

- ICD (Implantable Cardioverter Defibrillator) takilmasi, tek elektrod (P700700)

- Kalıcı kalp pili değiştirilmesi, Jeneratör (P700690)

- Kalıc kalp pili lead çıkartılması (P700731)

- Kalıc1 kalp pili takılması (atriyoventriküler) (P700670)

- Kalıc kalp pili veya ICD elektrodu değiştirilmesi (P700691)

- Perkütan transluminal koroner anjiyoplasti ve stent, tek damar (P700910)

- Perkütan transluminal koroner artere direkt stent (P700921)

- Sağ kalp kateterizasyonu (P700740)

- Sağ ve sol kalp kateterizasyonu (P700780)

- Sol kalp kateterizasyonu (P700760) olduğu hiçbir ortak işlemde ise tahakkuk kârı olmadığı görüldü.

Paket detayları incelendiğinde A hastanesinde verilen tüm hizmet giderlerinin tahakkuk edildiği ve tahakkuk zararlarinin sebeplerinden birinin bu durum olduğu görüldü. A hastanesinde ek tanıları olan daha komplike hastaların tedavi edildiği tanılardan ve paket detaylarından anlaşıldı. A hastanesi faturalandırma prensipleri incelendiğinde preoperatif yatışların pakete dahil edildiği ve malzeme giderlerinin fazla olduğu görüldü. B hastanesi paket detaylarında çoğu işlemlerde, olmazsa olmaz ilaç ve malzemelerin dahi tahakkuk edilmediği, bu nedenle tahakkuk zararı oluşmadığı dikkati çekti. B hastanesi hasta özelliklerine bakıld1ğında hastanede kalıș süresinin kısa olduğu ve ek tanısı olmayan stabil hastaların tedavi edildiği görüldü. $\mathrm{B}$ hastanesi faturalandirma prensiplerine bakıldığında preoperatif yatış sürelerinin hizmet başı olarak SGK' na ayrıca fatura edildiği dikkati çekti. C hastanesi paket detaylarında komplike hastalarda tahakkuk edilen hizmetlerin doğal olarak daha fazla olması nedeniyle aşımlar olurken, daha az riskli hastalarda eksik tahakkuklar olduğu görüldü. C hastanesi faturalandirma prensiplerine bakıldığında preoperatif yatış sürelerinin hizmet başı olarak SGK' na fatura edildiği dikkati çekti. Çalışma kapsamındaki paket işlemler için SGK' nun tüm malzeme, ilaç, kan bileşenleri, preop yatıș sürelerinin pakete dahil olarak değerlendirilmesinin de paket aşımlarına neden olduğu görüldü.

Çalışma kapsamındaki üç hastanenin Kardiyoloji ve KVC kliniklerinde ortak yapılan ve tahakkuk zararı oluşan on dört işlem için SUT fiyatlarının yeterli olmadığı, KVC Kliniklerinde ortak yapılan ve tahakkuk kârı oluşan sekiz işlem için SUT paket fiyatlarının yeterli olduğu ifade edilebilir. Paket detaylarının analizinde, paket așımlarının; hastanelerin faturalandirma prensiplerinden kaynaklanan farklılıklardan, hasta özelliklerinden kaynaklanan farkl1lıklardan ve SUT hükümlerine bağlı olarak SGK'ndan kaynaklanan durumlardan dolayı oluştuğusöylenebilir. Paket detayları incelendiğinde kan bileşenleri, ilaç ve tıbbi malzeme giderleri, hastanede kalış süresi ve yoğun bakım takip sürelerinin de paket aşımlarında önemli faktörler olduğu görüldü. Sağlık Uygulama Tebliği'nde hizmet başı fiyatların doğru analiz edilerek hazırlandığı varsayılsa dahi paket fiyatları toplam tahakkukların altında kalmaktadır. Dolayısıyla SUT hizmet başına ödeme listesi ile tanıya dayalı işlem listesi fiyat aralığında korelasyon olmadığ1 ifade edilebilir. Sosyal Güvenlik Kurumu SUT fiyatları ile hizmet sunmanın geri ödeme süreçlerinde yaşanan zorluklar ve kesintiler de düşünüldügünde üniversite hastanelerinin mali sürdürülebilirliklerini tehdit eden sonuçları olduğu kanaatine varıldı.

Çalışma sonucunda tahakkuk zararlarının azaltılması için, daha riskli hastaların tedavi edildiği üniversite hastanelerine özel SUT'nde belirtilen*' 11 işlemlerde $\% 10$ olan oranın artırılması, üç kamu üniversite hastanesinde de tahakkuk zararı oluşan işlemler için paket fiyatlarinin artirilmasi, ek tanisı olan hastalar için risk grupları göz önüne alınarak SUT'nde eşlik eden hastalık kapsamının genişletilmesi, preop yatış sürelerinin hizmet bașı olarak ayrıca faturalandırılabilmesi için SUT hükümlerinin netleştirilmesi, risk faktörlerine dayalı maliyet analizi çalışmalarının yapılması ve geri ödemede dikkate alınması gerektiği düşünüldü.
* SUT 2.2.2.B - Tanıya Dayalı İșlem Üzerinden Ödeme Yöntemi

(5) Kurumla sözleșmeli/protokollü üçüncü basamak resmi sağlık kurumlarınca yapılan SUT eki EK-2/C Listesinde yanında $\left({ }^{*}\right)$ ișareti olan ișlemler, listede belirtilen puanlara \%10 ilave edilerek faturalandırılır. 


\section{KAYNAKLAR}

1. Top M, Tarcan M, Hastane Sektöründe Kaynak Akıșı: Hastane Ödeme Yöntemleri. Gazi Üniversitesi İktisadi ve İdari Bilimler Dergisi 2007; 9: 169-189.

2. Aral A, Sağlikta Yeni Dönem DRG. Ankara: Bizim Akademi Yayınları; 2014.

3. Ağırbaş İ, Erkol Ü, Hastanelerde Maliyet Analizi ve Faaliyet Tabanlı Maliyetleme Yöntemine Dair Bir Uygulama. Ankara Üniversitesi Tip Fakültesi Mecmuası 2011;64: 87-95.

4. Çelik Y, Sağlık Ekonomisi. Ankara: Siyasal Kitapevi; 2011.

5. Yıldız G, Kurumsal Sağlık Hizmeti Sunucularından Hastanelere Yapılan Ödeme Yöntemlerine İlișkin Sorunların Algılanma Biçimleri: Ankara İli Uygulaması. Gazi Üniversitesi Sosyal bilimler Enstitüsü Hastane İşletmeciliği Bilim Dalı Yüksek Lisans Tezi; 2008.

6. Waters HR, Hussey P, Pricing Health Services For Purchasers-a Review of Methods and Experiences. Health Policy. 2004;7:175-184.
7. Akbulut Y, Sağlık Sigortacıllı̆ı. "Türkiye'de Sağlık Sigortacılığının Tarihsel Gelişimi” İçinde (Editör: Yıldırım, HH.) Anadolu Üniversitesi Yayınları, Yayın No: 2527, 2012, Eskişehir.

8. Tatar M,Tanıya Dayalı Gruplar ve Sağlık Hizmetleri Kaynak Gruplar1. 2008: http://pitstop.com.tr/taniya-dayaligruplar-ve-saglik-hizmeti-kaynakgruplari/. Erișim Tarihi Ağustos 15, 2014.

9. SUT Kilavuzu: www.ssk.gov.tr, Genel Sağlık Sigortası. Erişim Tarihi Temmuz 16,2014 .

10. Boyac1 Y.A, Üniversite Hastanelerinde Uygulanan Sağllk Paket Program Uygulamalarının Maliyet Analizi, Pamukkale Üniversitesi Eğitim Uygulama Ve Araştırma Hastanesinde Bir Uygulama. İstanbul Üniversitesi, Sosyal Bilimler Enstitüsü Yüksek Lisans Tezi; 2006.

11. Cakık Y, Sağlık Hizmetlerinde Katılım Pay1 Uygulaması Ve Bu Uygulamanın Sosyal Devlet İlkesi ve Sosyal Güvenlik Hakkı Bakımından İncelenmesi. Sayıștay Dergisi 2011; 80: 85-105.
12. Eminsoy G.M, Paket Ameliyatlardan Laparoskopik Kolesistektominin Hizmet Maliyetlerinin Belirlenmesi ve BUT-SUT Fiyatlarıyla Karșılaștırılması. Bașkent Üniversitesi Sosyal Bilimler Enstitüsï Yüksek Lisans Tezi; 2008.

13. Ceran Y, Özdemir C, Sağlık İșletmelerinde Paket İslem Fiyat Uygulamasının Hedef Maliyetleme Yöntemi ve Stratejik Pazarlama Muhasebesi Açısından Değerlendirilmesi ve Özel X Diyaliz Merkezinde Bir Uygulama. Selçuk Üniversitesi İktisadi ve İdari Bilimler Fakültesi Sosyal ve Ekonomik Araştırmalar Dergisi 2013; 26 450-478.

14. Aytekin V, Paket Fiyat Uygulamalar Hastayı mı Kurumları mı Korumaktadır? Türk Kardiyoloji Derneği Dergisi 2005; 33: 281-283.

15. Yılmaz M. B, Büyükkaramıklı C..N, Çakan $\mathrm{N}$, ve ark. Rasyonel Bir Maliyetlendirme Sistemi Risk Faktörlerini Göz Önüne Almali: Koroner Anjiyografi Paket Uygulamasının Değerlendirilmesi. Türk Kardiyoloji Derneği Arşivi 2005; 33:5. 